\title{
The importance of being psychologically empowered: Buffering the negative effects of employee perceptions of Leader-Member Exchange differentiation
}

\author{
Cécile Emery ${ }^{\prime} *$ (D), Jonathan E. Booth ${ }^{2}$ (D) , George Michaelides ${ }^{3}$ (D) \\ and Alexander J. Swaab ${ }^{4}$ \\ 'University of Surrey, Guildford, UK \\ ${ }^{2}$ London School of Economics and Political Science, UK \\ ${ }^{3}$ University of East Anglia, Norwich, UK \\ ${ }^{4}$ Alumna of the London School of Economics \& Political Science
}

\begin{abstract}
Although differentiated relationships among leaders and their followers are fundamental to Leader-Member Exchange (LMX) theory, research provides limited knowledge about whether employees' responses to individual perceptions of LMX differentiation are uniform. In a field study, we examined whether individual-level psychological empowerment buffers the negative relationship between perceived LMX differentiation and job satisfaction and found that the negative relationship is strongest under low employee psychological empowerment conditions, as compared to high psychological empowerment. Furthermore, in a multi-wave field study and an experiment, we extended these initial findings by investigating employees' perceptions of supervisory fairness as a mediator of this moderated relationship. We found that the indirect effect between perceived LMX differentiation and job satisfaction, through supervisory fairness perceptions, is strongest under low employee psychological empowerment, as compared to high psychological empowerment. Collectively, our findings showcase the importance of psychological empowerment as a tool for employees to use to counteract the negative effect of perceived differentiated contexts.
\end{abstract}

\section{Practitioner points}

- When employees perceive that their managers have differentiated relationships across workgroup employees, employees tend to be less satisfied in their jobs, and this negative relationship is explained through employees' perceptions of supervisory fairness.

- Employees with low psychological empowerment levels (e.g., employees who feel less in control of their work) report lower levels of job satisfaction when they perceive that their managers differentiate among employees.

- However, employees with high levels of psychological empowerment are more resilient in contexts where managers are perceived to differentiate across workgroup employees.

- The findings reinforce the necessity for managers and organizations to implement and promote empowerment initiatives.

This is an open access article under the terms of the Creative Commons Attribution-NonCommercial License, which permits use, distribution and reproduction in any medium, provided the original work is properly cited and is not used for commercial purposes.

*Correspondence should be addressed to Cecile Emery, University of Surrey, Stag Hill, Guildford GU2 7XH, UK (email: cecile.emery@surrey.ac.uk). 
More than 40 years of research have established the importance of the quality of leaderfollower dyadic relationships in the workplace (Martin, Epitropaki, Thomas, \& Topakas, 2010). While Leader-Member Exchange theory (hereafter, LMX; Graen \& Uhl-Bien, 1995) advocates that leaders should aim to develop high-quality relationships with their followers, the theory also states that leaders are unlikely to develop similar quality relationships with all of their followers (Liden, Sparrowe, \& Wayne, 1997). Given that leaders' time, effort, and resources are limited (Hooper \& Martin, 2008a), leaders differentiate among followers, developing high-quality relationships with certain employees and not with others, a process that is referred to as LMX differentiation (e.g., Henderson, Liden, Glibkowski, \& Chaudhry, 2009). Although it is a central premise of LMX theory, LMX differentiation has only recently gained momentum in the literature (Epitropaki et al., 2016), with a growing number of papers theoretically conceptualizing LMX differentiation as a group-level process and operationalizing it as the standard deviation across workgroup members' LMX scores (Martin, Thomas, Legood, \& Dello Russo, 2018). While this burgeoning literature has shed light on LMX differentiation and its outcomes, particularly at the group-level of analysis (Anand, Hu, Liden, \& Vidyarthi, 2011; for a meta-analysis, see Yu, Matta, \& Cornfield, 2018), relatively, little is known about individual-level perceptions of LMX differentiation and how employees respond to these perceptions (Anand et al., 2011; Hooper \& Martin, 2008a; Kauppila, 2016; Van Breukelen, Konst, \& Van Der Vlist, 2002; Van Breukelen, Van Der Leeden, Wesselius, \& Hoes, 2012). As leaders practice differentiation in at least $80 \%$ of workgroups (Liden \& Graen, 1980), LMX differentiation appears to be the norm, rather than the exception, in workgroups. Therefore, it is of great importance to both researchers and managers to further the current understanding of perceived LMX differentiation, its potential consequences, and mechanisms that explain these relationships, especially when employees' perceptions of their work environment have stronger influences on workplace attitudes and behaviours than the actual environmental reality (Kristof-Brown, Zimmerman, \& Johnson, 2005).

Perceived LMX differentiation (hereafter, PLMXD) is defined as the extent to which LMX relationships are perceived to vary within a workgroup by a focal employee (Hooper \& Martin, 2008a). As PLMXD is a perceptual measure and operates at the individual level of analysis, it is likely to be a better predictor of individual-level outcomes than group-level LMX differentiation (Anand, Vidyarthi, \& Park, 2015; Anand et al., 2011; Hooper \& Martin, 2008a; Thomas, Martin, Epitropaki, Guillaume, \& Lee, 2013). Only a handful of empirical studies have examined the individual-level outcomes of PLMXD. These studies have revealed that employees with higher levels of PLMXD tend to report greater levels of team conflict, as well as decreased job satisfaction, well-being, (Hooper \& Martin, 2008a), group commitment (Van Breukelen et al., 2002), team-atmosphere (Van Breukelen et al., 2012), and trust in teammates (Yuan \& Jian, 2012).

Although evidence exists regarding the negative influence of PLMXD on employee outcomes, limited research has investigated the mechanisms that can explain the relationship between PLMXD and employee outcomes. Additionally, the PLMXD literature has primarily assumed uniform employee responses to PLMXD; thus, research has yet to explore the boundary conditions of PLMXD and whether employees respond differently to PLMXD under certain workplace conditions. In this paper, we contribute to the LMX differentiation literature by developing and testing a theoretical conditional mediation model to understand how PLMXD operates. We specifically focus on employee job satisfaction as our outcome of interest, as it is a diagnostic tool that employers commonly use to gauge whether their employees' 
experiences at work are favourable. Given that researchers and policy makers have determined a general downward trend in employee job satisfaction across the globe (Green, Felstead, Gallie, \& Inanc, 2013; Rose, 2005), it is important to determine the specific work conditions that potentially contribute to and buffer negative job satisfaction.

Using organizational justice theory, we posit that followers' perceptions of supervisory fairness (i.e., an employee's evaluation of whether the leader treats group members fairly; Blader \& Tyler, 2003) explain the negative indirect relationship between PLMXD and job satisfaction. Previous scholarly work has focused on workgroup conflict and distrust as explanatory mechanisms (Hooper \& Martin, 2008a; Yuan \& Jian, 2012). However, in our theorizing to clarify the indirect relationship, we highlight supervisory fairness perceptions, a more proximal explanatory mechanism that followers use as an initial evaluation of PLMXD, which occurs before workgroup conflict or distrust. While Hooper and Martin (2008a, 2008b) have theoretically posited fairness perceptions as an explanation for the relationship between PLMXD and employee attitudes, this theoretical mechanism has yet to be empirically tested. To our knowledge, we provide the first empirical examination of the theory that supervisory fairness perceptions mediate the indirect relationship between PLMXD and job satisfaction.

Furthermore, we propose that psychological empowerment (i.e., a cognitive state achieved when employees feel in control of their work; Spreitzer, 1995) is a boundary condition of the negative indirect relationship between PLMXD and job satisfaction through supervisory fairness. More precisely, we posit that the negative indirect effect between PLMXD and job satisfaction will be buffered by high levels of psychological empowerment; thus, the negative indirect relationship between PLMXD and job satisfaction through supervisory fairness will be stronger under low levels of psychological empowerment. We suggest that the buffering effect occurs because high levels of psychological empowerment provide employees with fairness perceptions (Chi \& Han, 2008; Ritter, Venkatraman, \& Schlauch, 2014) that can counterbalance or compensate for the supervisory unfairness perceptions that employees experience as PLMXD increases (see Figure 1). By revealing that employees do not necessarily respond uniformly to PLMXD, we inform managers and organizations about the opportunity to establish work contexts that can potentially prevent employees from experiencing negative outcomes of PLMXD.

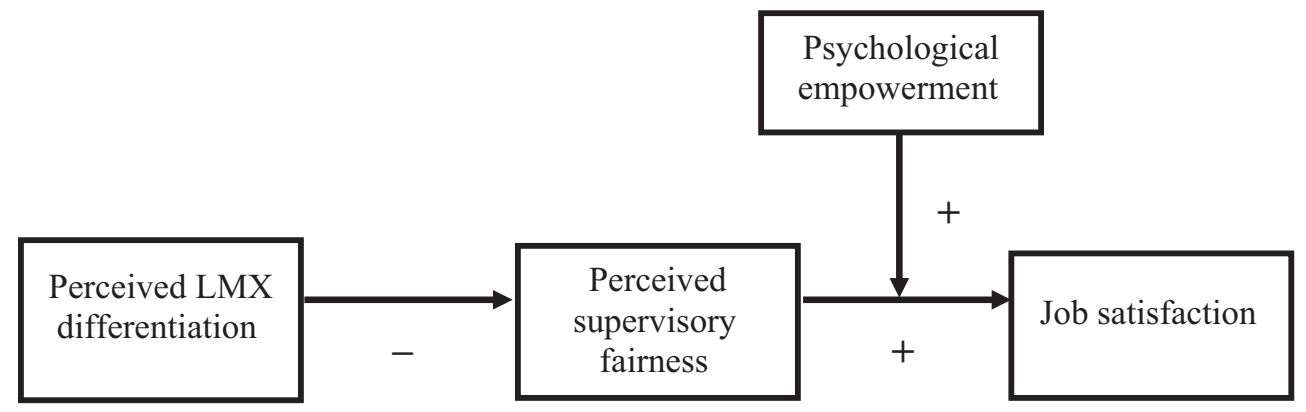

Figure I. Theoretical model. 


\section{Theory and hypotheses}

The mediating effect of perceived supervisory fairness

Only a handful of empirical studies have examined the phenomenon of LMX differentiation at the individual level; that is, 'individual perceptions of how much the leader differentiates amongst the group members' (Anand et al., 2011, p. 313). Altogether, these studies suggest that employees prefer equality and consistency in their workgroup, as a leader's differentiated treatment can elicit employees to question their leader's fairness and can undermine team dynamics (see Anand et al., 2015, for a review). For example, Sias and Jablin (1995) found that employees who perceived that their leader differentiated his or her treatment of employees not only considered this unfair but also reduced their communication with 'favoured' fellow group members. Van Breukelen et al.'s (2012) findings also demonstrate that followers' perceptions of their leader's differential treatment regarding socioemotional issues (e.g., sympathy) and task issues (e.g., influence on team strategy) cause followers to develop negative perceptions of their team environment and performance. These scholars have suggested that these negative relationships are a result of employees doubting the fairness and integrity of their leader. Additionally, other studies have explicitly supported explanatory mechanisms, such as team conflict and distrust, to explain the indirect negative relationship between PLMXD and individual-level outcomes (Hooper \& Martin, 2008a; Yuan \& Jian, 2012).

Organizational justice theory helps to explain why employees prefer equality and consistent treatment across members in their workgroup and, hence, why PLMXD has generally been associated with negative individual-level consequences (Martin et al., 2018). In differentiated workgroups, high-LMX members benefit from greater access to tangible and intangible resources (Liden et al., 1997), while low-LMX members have access to little or no resources allocated by the leader (Scandura, 1999). LMX differentiation hence violates the norm of equality, which espouses that individuals prefer equitable, consistent treatment when they are part of a social group (Deutsch, 1975). Such differentiation further contradicts the general premise that leaders must treat workgroup members similarly to be considered procedurally fair (Leventhal, 1980; Scandura, 1999). Additionally, PLMXD goes against the leader's supposed neutrality (Leventhal, 1980). According to relational models of justice, such as Tyler's (1989) groupvalue model, leader neutrality toward group members is a key factor that determines supervisory fairness perceptions (Lind \& Tyler, 1988; Tyler, 1989); that is, leaders must act in a neutral, consistent, and unbiased way toward group members to be perceived as fair (Tyler, 1990). Leaders who treat workgroup members unequally - for example, by allocating more resources to high-LMX employees - break their neutrality and convey the message that not everyone is valued in the same way (Blader \& Tyler, 2015; Lind \& Tyler, 1988), which is likely to trigger perceptions of supervisory unfairness (Leventhal, 1980; Scandura, 1999). As PLMXD can be associated with perceived 'non-neutrality on the leaders' part' (Hooper \& Martin, 2008a, p. 22), Hooper and Martin (2008a, 2008b) have suggested that it directly impacts employees' perceptions of supervisory fairness.

Once formed, perceived unfairness of supervisory interactions with workgroup members can lead to a series of negative outcomes. For example, unfairness perceptions have been associated with distrust, dislike, and disrespect (Sias \& Jablin, 1995), envy (Vecchio, 2005) toward high-LMX co-workers, and feelings of relative deprivation (Bolino \& Turnley, 2009). Previous literature has also consistently found that justice perceptions significantly influence organizational outcomes, including job satisfaction (for a metaanalytic review, see Colquitt, Conlon, Wesson, Porter, \& Ng, 2001; Blader \& Tyler, 2003; 
Leventhal, 1980; McFarlin \& Sweeney, 1992; Scandura, 1999). Hence, this implies that individuals see PLMXD as less fair to the workgroup (Anand et al., 2015; Blader \& Tyler, 2003; Scandura, 1999), which can lead to weakened individual perceptions of team and work-related outcomes (e.g., Hooper \& Martin, 2008a; Yuan \& Jian, 2012). In summary, we expect the relationship between PLMXD and job satisfaction to be explained through employees' supervisory fairness perceptions.

Hypothesis 1: Supervisory fairness perceptions mediate the relationship between PLMXD and job satisfaction.

The moderating effect of psychological empowerment

Psychological empowerment is defined as an 'intrinsic task motivation reflecting a sense of self-control in relation to one's work and an active involvement with one's work role' (Seibert, Wang, \& Courtright, 2011, p. 981). It encompasses four dimensions: meaning (when employees' work goals and values are in line with their life goals and values); competence (when employees believe that they are capable of skilfully performing their work activities); self-determination (when employees have autonomy or control over their work); and impact (when individuals have personal influence on operating outcomes and their work environment; Spreitzer, 1995). Over the last two decades, extensive research has documented the importance of psychological empowerment by demonstrating that empowered employees perform better in their jobs (Spreitzer, Kizilos, \& Nason, 1997), exhibit more organizational citizenship behaviours (Seibert et al., 2011), are more committed to their organization (Chen \& Kanfer, 2006), and experience greater job satisfaction (Harris, Wheeler, \& Kacmar, 2009; Liden, Wayne, \& Sparrowe, 2000; Seibert, Silver, \& Randolph, 2004; Seibert et al., 2011).

Two meta-analytic reviews (Maynard, Gilson, \& Mathieu, 2012; Seibert et al., 2011) highlight the many antecedents of psychological empowerment, such as structural empowerment (e.g., when management transfers autonomy and responsibility to lowerlevel employees), individual characteristics (e.g., age, tenure, job level, and personality), organizational support (e.g., culture, climate, and centralization), work design (e.g., task significance, task complexity, skill variety, and feedback), and leadership. LMX is listed as a leadership-antecedent of psychological empowerment, given that employees embedded in high-LMX relationships have access to higher levels of task variety (Dunegan, Duchon, \& Uhl-Bien, 1992), decision influence (Liden \& Graen, 1980), and self-worth (Keller \& Dansereau, 1995), all of which are key ingredients of empowerment (Liden et al., 2000). Yet, as employees can define their sense of meaning, competence, selfdetermination, and impact from sources other than their relationships with their leaders, it is possible for low-LMX employees to also feel psychologically empowered in their work. We hence discuss how psychological empowerment has the potential to buffer the negative influence of PLMXD on job satisfaction through supervisory unfairness perceptions.

In order to explicate the role of psychological empowerment in buffering the association between supervisory unfairness and job satisfaction, we draw on organizational justice theory. According to instrumental models of justice (Thibaut \& Walker, 1975; Tyler, 1989), employees are motivated to seek more control over work procedures, as this can maximize the favourability of long-term outcomes. With greater control over their work processes, employees have been shown to experience increased fairness perceptions (Cohen-Charash \& Spector, 2001; Colquitt et al., 2001; Thibaut \& Walker, 1975; Tyler, 1990). Extensive scholarly investigations have explored the role of 
psychological empowerment in providing such control over employees' work processes. Psychologically empowered employees: (1) are confident in their ability to perform their daily tasks (Spreitzer, 1995); (2) trust that they have an impact on their work environment (Spreitzer, 1996); (3) actively contribute to reaching organizational goals (Maynard et al., 2012; Seibert et al., 2011); and (4) have a greater tendency to voice their opinions (Chamberlin, Newton, \& LePine, 2018; Raub \& Robert, 2013). The above research promotes the theory that psychological empowerment grants employees self-efficacy and a voice in the workplace, and enables them to participate in decision making, which are key elements of instrumental control overwork processes. Aligned with the employee involvement and fairness relationship established in the organizational justice literature, the positive association between psychological empowerment and fairness perceptions is theoretically and empirically supported (Chi \& Han, 2008; Ritter et al., 2014).

Considering the instrumental control and perceived fairness that psychological empowerment offers employees, psychological empowerment could play an influential role in counterbalancing employees' supervisory unfairness perceptions that arise from PLMXD. Therefore, we posit that psychological empowerment should moderate the relationship between supervisory fairness perceptions and job satisfaction. In our proposal of this, we turn to Blader and Tyler's (2003) component model of justice, which states that people are influenced by two aspects of formal procedures when making fairness judgements: those aspects that relate to employee involvement and participation (i.e., psychological empowerment) and those that relate to the treatment quality that group members receive (i.e., PLMXD and the perception of supervisory unfairness it causes). While relational models of justice suggest that PLMXD lowers the treatment quality that group members receive from their leader (Blader \& Tyler, 2003), thereby creating perceptions of supervisory unfairness that lead to lower levels of job satisfaction, instrumental models of justice (Thibaut \& Walker, 1975) suggest that psychological empowerment positively affects fairness perceptions, due to the greater involvement and participation it provides (Blader \& Tyler, 2003). In summary, a higher level of psychological empowerment has the potential to buffer the negative effects of perceived supervisory unfairness on job satisfaction, as it compensates for the fairness perceptions that PLMXD reduce.

If employees who report greater PLMXD are empowered, these employees are more likely to remain satisfied in their jobs, as the fairness perceptions they derive from their feelings of empowerment can counterbalance the supervisory unfairness perceptions experienced as a result of PLMXD. In contrast, when levels of psychological empowerment are low, the negative consequences of PLMXD will be fully experienced, as unfairness perceptions related to PLMXD will not be compensated for by the benefits of empowerment. Our theory here is aligned with the work of Reb, Goldman, Kray, and Cropanzano (2006), who established that, when procedural injustice occurs (e.g., perceived LMX differentiation), instrumental remedies (e.g., remedies designed to address employees' need for control, such as psychological empowerment) are most effective in positively adjusting that injustice. In summary, this suggests that psychological empowerment can act as an instrumental remedy that buffers the negative effects of PLMXD on job satisfaction through supervisory unfairness perceptions.

Hypothesis 2: Psychological empowerment moderates the relationship between PLMXD and job satisfaction via supervisory fairness perceptions, such that the mediated relationship will be stronger under low levels of psychological empowerment than high levels of psychological empowerment. 
We conduct three studies that collectively provide evidence that psychological empowerment is important in combating the negative effects of PLMXD. Our pilot field study (Study 1) provides preliminary evidence that psychological empowerment moderates the negative relationship between PLMXD and job satisfaction. As Study 1 was conducted with employees from one organization, it strengthens the ecological validity to our overall investigation. This initial indicator that the PLMXD-job satisfaction relationship may not be uniform provides impetus to Studies 2 and 3 which test our complete theoretical model. These additional studies investigate (1) employee supervisory fairness perceptions as an explanatory mechanism between PLMXD and job satisfaction (Hypothesis 1) and (2) the moderating effect of psychological empowerment on this mediated relationship (Hypothesis 2). In Study 2, we test our moderated-mediation model using a working sample with multi-wave design over three time periods. Study 3 similarly uses a working sample and constructively replicates Study 2 with betweensubject random assignment experimental design. Our approach with different research designs aids in dealing with potential issues related to threats to internal and external validity.

\section{STUDY I: PILOT FIELD STUDY}

\section{Sample and procedure}

To understand whether or not employees respond uniformly to PLMXD, we used twowave data collected from participants employed by a beverage production company based in the Republic of North Macedonia. Participation was on a voluntary basis, and confidentiality and anonymity were assured. All 266 employees were invited to take part in our study. To minimize common source and common method concerns, the surveys were split into two parts, with a 1-week time lag (Podsakoff, MacKenzie, \& Podsakoff, 2012). Two hundred and thirty-seven employees took the first survey, designed to measure PLMXD. A week later, 221 employees took the second survey, designed to measure psychological empowerment and job satisfaction. Two hundred and eighteen employees were present at both rounds of data collection. We removed seven suspect responses as well as incomplete responses from the data set. In total, 157 sets of valid, matched questionnaires were obtained, signifying a final response rate of $59 \%$. Among the 157 employees in our final sample, 54\% were men and $42 \%$ had obtained an undergraduate degree or above. The average age was 44 years $(S D=11.6)$.

\section{Measures}

All items were originally developed in English. We employed back-translation procedures (Brislin, 1970) to translate the items into Macedonian. Unless specified otherwise, all responses were rated on a 7 -point Likert scale $(1=$ strongly disagree to $7=$ strongly agree).

\section{Perceived LMX Differentiation (PLMXD)}

We relied on indirect individual-source data to provide estimates of employees' assessments of whether their co-workers were close or distant from the leader (Martin et al., 2018). While it would have been possible to assess PLMXD by directly asking employees about their judgments regarding the extent to which their leader treats group members differently (i.e., direct measurement; see, for example, Van Breukelen 
et al.'s, 2012 study), we chose to calculate it from the individuals' estimates (i.e., indirect measurement), using the measurement developed by Hooper and Martin (2008a).

Participants were required to indicate the number of people in their team, including themselves, whose relationship quality with the leader could be described as either 'very poor' (1), 'poor' (2), 'satisfactory' (3), 'good' (4), or 'very good' (5). In other words, participants were asked to sort their team on the basis of different categories of relationship quality with the leader. For each participant, we computed the coefficient of variation (i.e., the standard deviation of the respondent's LMX scores for each of his or her teammates, divided by the mean average score) to assess the perceived LMX differentiation. The coefficient of variation describes the dispersion of a variable; the higher the coefficient of variation, the greater the dispersion in the variable and, in this case, the greater the perceived LMX differentiation.

\section{Psychological empowerment}

We used a 12-item empowerment scale (Spreitzer, 1995). Example items are: 'The work I do is meaningful to me', 'I am confident about my ability to do my job', 'I have significant autonomy in determining how I do my job', and 'My impact on what happens in my department is large'. The Cronbach's alpha of the composite score of psychological empowerment was .87 .

\section{Job satisfaction}

We used five items from Brayfield and Rothe's (1951) scale. Items were as follows: 'I find real enjoyment in my work', 'Most days, I am enthusiastic about my work', 'I feel satisfied with my present job', and 'I consider my job rather unpleasant' (reversed coded). After following Brislin's (1970) suggestions for back and forth translations, a fifth item ('Each day seems like it will never end') was deemed by company management and researchers as inappropriate for participants to answer; thus, the item was dropped. The Cronbach's alpha for the four items was .81 .

\section{Controls}

We controlled for three established predictors of job satisfaction: education $(1=$ secondary school; 2 = undergraduate; 3 = master's; and 4 = doctorate; Mora, Aracil, \& Vila, 2007); tenure with manager (in years); and LMX(Gerstner \& Day, 1997). Individual LMX scores were obtained using the LMX-7 scale (Graen \& Uhl-Bien, 1995). An example item is: 'I would characterize my working relationship with my supervisor as extremely effective'. The LMX Cronbach's alpha was .91.

\section{Results}

Table 1 presents descriptive statistics, ICC1, correlations, and Cronbach's alphas for all variables in Study 1. Our data are nested within 21 teams and the intra-class correlation for job satisfaction is high enough (ICC1 $=.15$; Table 1 ) to suggest that using linear regression would violate the assumption of independence of error. We therefore used multilevel regressions to evaluate the moderating effect of psychological empowerment on the relationship between PLMXD and job satisfaction. We ran our analyses using $\mathrm{R}$ 
Table I. Study I: Means, standard deviations, ICCI, and correlations $(N=156)$

\begin{tabular}{|c|c|c|c|c|c|c|c|c|}
\hline & \multicolumn{2}{|c|}{ Descriptive } & \multirow[b]{2}{*}{$\mathrm{ICCl}$} & \multicolumn{5}{|c|}{ Correlations } \\
\hline & $M$ & $S D$ & & I & 2 & 3 & 4 & 5 \\
\hline I. Job satisfaction & 5.47 & 1.18 & .15 & $(.8 \mathrm{I})$ & & & & \\
\hline 2. PLMXD & 0.10 & 0.14 & .00 & $-.17^{*}$ & & & & \\
\hline 3. Psych. Empowerment & 5.78 & 0.82 & .02 & $.53 * * *$ & -.11 & $(.87)$ & & \\
\hline 4. LMX & 5.05 & 1.39 & .14 & $.4 I^{* * *}$ & -.15 & $.40 * * *$ & $(.91)$ & \\
\hline 5. Tenure manager & 8.24 & 8.56 & .08 & -.07 & -.04 & .05 & -.10 & \\
\hline 6. Education & 1.47 & 0.61 & .32 & $.27 * * *$ & $.20 *$ & $.16 *$ & .04 & $.18^{\prime}$ \\
\hline
\end{tabular}

Notes. Values in parentheses Cronbach's alpha.

Two-tailed test. $* p<.05 ; * * p<.01 ; * * * p<.001$.

3.4.1 (R Core Team, 2018) and the lme4 package (Bates, Maechler, Bolker, \& Walker, 2015). Interaction variables (PLMXD and psychological empowerment) were grand-mean centred and scaled to ease the interpretation of the coefficients.

We ran three multilevel models. Model 1 contains the control variables only (education, tenure with manager, and LMX). Main effects (PLMXD and psychological empowerment) were added in Model 2. Finally, Model 3 includes the interaction between PLMXD and psychological empowerment. The results from all three multilevel regression models are reported in Table 2. The main effect of psychological empowerment on job satisfaction was found to be significant (Model 3: $\beta=0.46$, $S E=.08, p<.001$ ) but the main effect of PLMXD was not (Model 3: $\beta=-0.08$, $S E=.08, p>.05)$. The interaction term was found to be positive and significant $(\beta=0.19, S E=.07, p<.01)$. To check for potential multicollinearity issues, we estimated the variance inflation factor (VIF) on our third model, which was revealed to be fairly small for all variables (ranging from 1.02 to 1.23 ), indicating that there were no multicollinearity issues between any of our predictors. To illustrate the pattern of the interaction effect, we applied Aiken and West's approach (1991) and used one standard deviation below and above the mean of empowerment to present high and low levels of psychological empowerment. Figure 2 illustrates how employees who reported lower levels of psychological empowerment were significantly less satisfied with their job when they perceived that the level of LMX differentiation was high (slope: $\beta=-0.27, t=-3.01, p<0.01$ ). On the other hand, employees who felt empowered in their daily job were not affected by their perceptions of LMX differentiation and remained equally satisfied (slope: $\beta=0.12$, $t=1.00, p=$ n.s.).

\section{STUDY 2: MULTI-WAVE FIELD STUDY}

Study 1 provides preliminary support that the negative influence of PLMXD is not uniform for all employees. Study 2 uses a sample of employed participants over three time waves and serves as an extension of the findings captured in Study 1. Specifically, Study 2 extends the first study by investigating employees' supervisory fairness perceptions as an explanation for the relationship between PLMXD and job satisfaction (Hypothesis 1) and by determining the conditional influence of psychological empowerment on this indirect relationship (Hypothesis 2). 


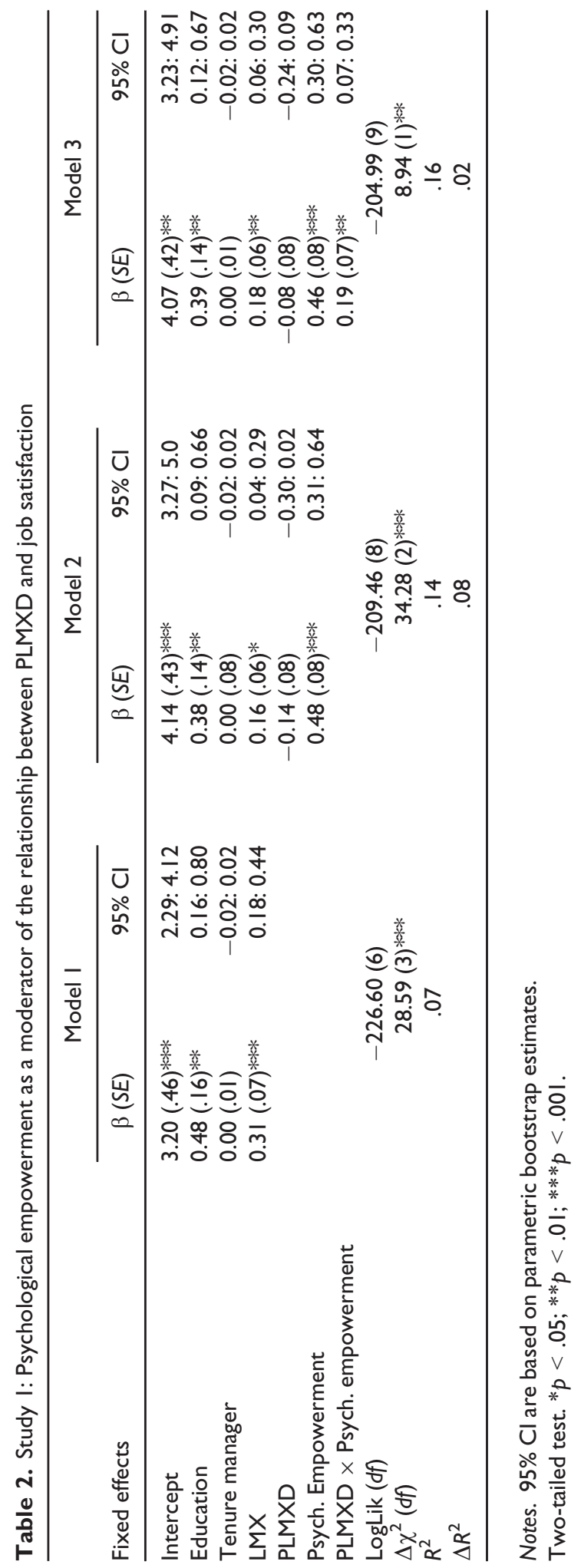




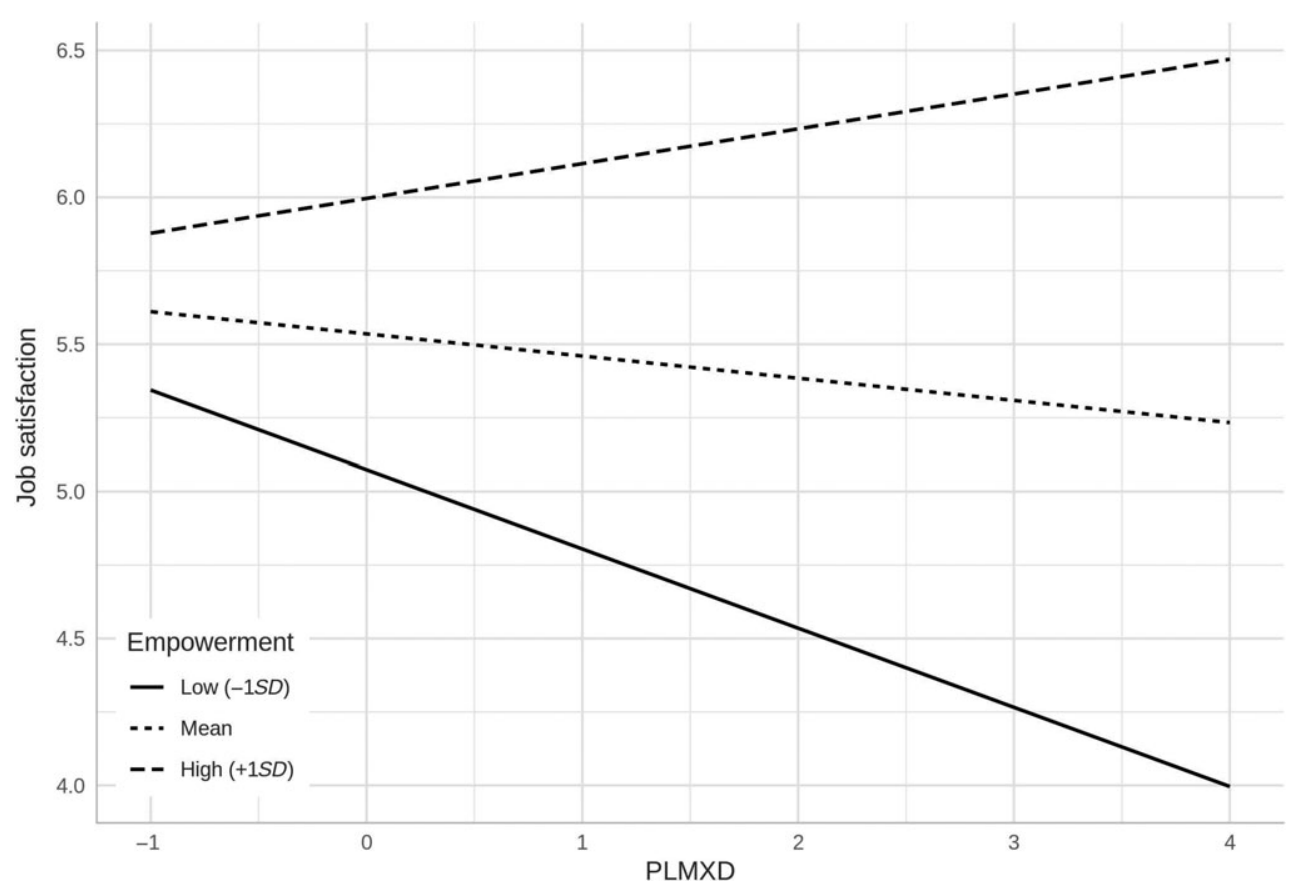

Figure 2. Study I: The moderating effect of psychological empowerment on the relationship between perceived LMX differentiation and job satisfaction.

\section{Sample and procedure}

We used a UK online panel provider, Pureprofile, to recruit UK participants for the threewave study. Participants were compensated $£ 1$ for each survey completed. Participation was voluntary, with confidentiality and anonymity assured. Pureprofile notified 1,296 individuals about our study; 71 individuals opted out before starting the survey. Given we had little control over participant selection, we implemented screening criteria. To participate in our study, participants needed to indicate that he or she is employed and working in his or her current position(468 screened out), for a direct supervisor (150 screened out), and in a team (78 screened out) for at least 3 months. ${ }^{1}$ We also removed those who reported a duplicate Pureprofile participant ID number or IP address (12 removed) and those who did not pass survey attention checks (86 removed).As a result, we had 431 participants in our Time 1 survey. Due to missing data, we further removed eight observations.

Thus, we invited the 423 participants from Time 1 to take the Time 2 survey, scheduled a week later. Three hundred and seventy-four responded to the Time 2 invitation; however, 17 chose to not proceed with the survey. As we required participants to remain employed and in the same job, working for the same supervisor and in the same team as the previous week, 30 participants were screened out. Therefore, 327 completed the Time 2 survey and were invited to take the Time 3 survey, scheduled a week later. Two hundred and eighty-two responded to the Time 3 invitation. Seven individuals chose not to continue with the Time 3 survey, while 13 were screened out as their employment,

\footnotetext{
I Scholars have determined that team socialization can take up to 3 months (e.g., Chen \& Klimoski, 2003).
} 
supervisor, or team status had changed since the previous week report. In total, 262 participants completed the Time 3 survey with a response rate of $62 \%$ (262 out of 423). After merging the three waves of data together and calculating scores for our constructs, 18 participants improperly reported PLMXD at Time 1, and these observations were dropped. Thus, 244 sets of valid, three time wave matched questionnaires remained. Among the 244 participants, $49 \%$ were men, $43 \%$ had an undergraduate degree or higher, and the average age was 51 years $(S D=10.23)$. We note that we did not have duplicate IP addresses or participant ID numbers reported in the last two waves. We also used attention checks in the last two waves. As we were concerned about attrition especially at Time 2 and 3, we did not remove those who failed attention checks. However, we did conduct our analyses with and without attention check fail observations, and our results were the same.

In the first wave of data collection, we captured PLMXD, psychological empowerment, and controls (i.e., LMX and employee's tenure with manager). Although psychological empowerment is a second-stage moderator in our model, psychological empowerment was collected at Time 1 , as we did not want it to be confounded with the fairness mediator (Time 2) or the job satisfaction outcome (Time 3). In the second wave, we captured employees' perceptions of supervisory fairness. In the third wave, we collected job satisfaction. Descriptive statistics, correlations, and Cronbach's alphas of all variables are reported in Table 3.

\section{Measures}

We measured PLMXD, psychological empowerment, job satisfaction, and LMX (control) using the same scales as in Study 1. To measure perceived supervisory fairness, we adapted Kim and Leung's (2007) 3-item scale, in order to capture perceptions of the leader's fair treatment of team members. An example item is 'My supervisor treats the members of my team fairly'. Items were assessed on a 7-point Likert ( $1=$ strongly disagree to $7=$ strongly agree). Table 3 presents descriptive statistics, correlations, and Cronbach's alphas for all variables in Study 2.

To ensure that our measures formed distinct constructs, we fitted a confirmatory factor analysis model for all of our latent variables (supervisory fairness, psychological empowerment, LMX, and job satisfaction), which had very good fit $\left(\chi^{2}=641.74\right.$, $d f=314, p<.001 ;$ CFI $=.95 ;$ TFI $=.95 ;$ RMSEA $=.07, p<.001 ;$ SRMS $=.06)$. We then

Table 3. Study 2: Means, standard deviations, and correlations $(N=244)$

\begin{tabular}{|c|c|c|c|c|c|c|c|}
\hline & \multicolumn{2}{|c|}{ Descriptive } & \multicolumn{5}{|c|}{ Correlations } \\
\hline & $M$ & $S D$ & I & 2 & 3 & 4 & 5 \\
\hline I. Job satisfaction (T3) & 4.94 & 1.29 & $(.91)$ & & & & \\
\hline 2. PLMXD (TI) & 0.11 & 0.13 & $-.31 * * *$ & & & & \\
\hline 3. $\operatorname{LMX}(\mathrm{TI})$ & 4.96 & 1.34 & $.67^{* * * *}$ & $-.27 * * *$ & $(.96)$ & & \\
\hline 4. Psych. Empowerment (TI) & 5.04 & 0.99 & $.71 * * * *$ & $-.23 * * *$ & $.68^{* * * *}$ & $(.91)$ & \\
\hline 5. Supervisory fairness (T2) & 4.93 & 1.46 & $.63^{* * * *}$ & $-.32^{* * * *}$ & $.80 * * *$ & .56 **** & $(.95)$ \\
\hline 6. Tenure with manager (TI) & 5.31 & 5.30 & $.17 * *$ & $-.17^{* *}$ & $.13 *$ & $.14^{*}$ & $.15^{*}$ \\
\hline
\end{tabular}

Notes. Values in parentheses Cronbach's alpha. TI = Time I, T2 $=$ Time 2, T3 = Time 3.

Two-tailed test. $* p<.05 ; * * p<.01 ; * * p<.001$. 
compared that model to one in which all the items were loaded onto a single factor $\left(\chi^{2}=2893.30, d f=324, p<.001 ; \quad \mathrm{CFI}=.61 ; \quad\right.$ TFI $=.58 ; \quad \mathrm{RMSEA}=.18, \quad p<.001 ;$ SRMS $=.11)$. The results indicate that the measures are distinct constructs and the multi-factor model is significantly better than the single factor model $\left(\Delta \chi^{2}=2251.56\right.$, $d f=10, p<.001)$.

\section{Results}

To test supervisory fairness as a mediator, we followed Hayes' (2018) PROCESS Model 4 in SPSS 24 (i.e., a mediation model), using unstandardized coefficients and bootstrapping with 10,000 resamples to place $95 \%$ bias-corrected confidence intervals around our estimates. The findings showed that PLMXD was negatively related to employees' perceptions of supervisory fairness, $\beta=-1.13, S E=.43, p<.01 ; F(3,240)=153.19$, $p<.001, R^{2}=.66$, and fairness perceptions positively related to job satisfaction, $\beta=0.19, S E=.07, p<.01 ; F(4,239)=57.49, p<.001, R^{2}=.49$, i.e., controlling for LMX and tenure with manager. The direct effect between PLMXD and job satisfaction was also significant $(\beta=-1.05, S E=.48, p<.05)$. When combining these estimates, the coefficient for the indirect effect of PLMXD on job satisfaction via fairness was -0.22 with 95\% CI [-0.49; -0.03], supporting our Hypothesis 1.

To examine the conditional indirect effect, we used Model 14 in SPSS PROCESS macro (Hayes, 2018), with the interaction term comprising the product of mean-centred fairness and empowerment, using unstandardized variables and calculated 95\% confidence intervals from 10,000 bootstrapped samples. Table 4 shows the results from the model which amounted to $61 \%$ of the variance for job satisfaction and $66 \%$ for supervisory fairness perceptions. PLMXD has a significant negative effect on supervisory fairness perceptions $(\beta=-1.13, S E=.43, p<.01)$ and a significant negative effect on job satisfaction $(\beta=-0.93, S E=.42, p<.05)$. Supervisory fairness perceptions has a significant positive effect on job satisfaction $(\beta=0.19, S E=.06, p<.01)$. When effects

Table 4. Study 2: Moderated-mediation analyses using psychological empowerment as a moderator of the relationships among PLMXD, fairness, and job satisfaction

\begin{tabular}{|c|c|c|c|c|}
\hline & \multicolumn{2}{|c|}{ PLMXD - Fairness } & \multicolumn{2}{|c|}{$\begin{array}{c}\text { PLMXD - Fairness - Job } \\
\text { satisfaction }\end{array}$} \\
\hline & \multicolumn{2}{|c|}{ Fairness (T2) } & \multicolumn{2}{|c|}{ Job Satisfaction (T3) } \\
\hline & $\beta(S E)$ & $95 \% \mathrm{Cl}$ & $\beta(S E)$ & $95 \% \mathrm{Cl}$ \\
\hline LMX (TI) & $0.84(.04)^{* * * *}$ & $0.75: 0.92$ & $0.13(.08)$ & $-0.02: 0.28$ \\
\hline Tenure with manager (TI) & $0.01(.01)$ & $-0.01: 0.03$ & $0.01(.01)$ & $-0.01: 0.03$ \\
\hline PLMXD (TI) & $-1.13(.43)^{* *}$ & $-1.98:-0.28$ & $-0.93(.42)^{*}$ & $-1.76:-0.10$ \\
\hline Supervisory fairness (T2) & & & $0.19(.06)^{* *}$ & $0.06: 0.31$ \\
\hline Psych. Empowerment (TI) & & & $0.61(.07)^{* * * *}$ & $0.46: 0.75$ \\
\hline $\begin{array}{l}\text { Fairness } \times \text { Psych. } \\
\text { Empowerment }\end{array}$ & & & $-0.07(.03)^{*}$ & $-0.13:-0.0$ \\
\hline Model summary & \multicolumn{2}{|c|}{$R^{2}=.66 ; F(3,240)=153.19 ; p<.001$} & \multicolumn{2}{|c|}{$R^{2}=.61 ; F(6,237)=61.44 ; p<.001$} \\
\hline
\end{tabular}

Notes. $\mathrm{TI}=$ Time I, $\mathrm{T} 2=$ Time $2, \mathrm{~T} 3=$ Time 3 .

Two-tailed test. $* p<.05 ; * * p<.01$ I ***p $<.001$. 
are combined, we produced a similar indirect effect coefficient, as above, confirming support for Hypothesis 1. Further, there was a significant positive effect of psychological empowerment $(\beta=0.61, S E=.07, p<.001)$ and a significant negative effect of the interaction between supervisory fairness and psychological empowerment $(\beta=-0.07$, $S E=.03, p<.05)$. Psychological empowerment moderates the mediation path so that when empowerment is low, the negative indirect effect of PLMXD through fairness (coefficient $=-0.28,95 \%$ CI $[-0.62:-0.06]$ ) is stronger than when empowerment is high (coefficient $=-0.13,95 \%$ CI $[-0.34: 0.03]$ ). The difference between the indirect effect for high and low empowerment was confirmed by a significant index of moderated mediation (index $=0.07,95 \%$ CI [0.01: 0.21]), supporting Hypothesis 2 .

\section{STUDY 3: EXPERIMENT}

To provide further evidence for our hypotheses, we constructively replicate (Lykken, 1968) our Study 2's findings using random assignment in experimental design with Study 3. Our studies in aggregate help us to better understand the internal and external validity of our findings. With its experimental design, Study 3 provides further evidence that employees' supervisory fairness perceptions are the explanatory mechanism between PLMXD and job satisfaction and that this indirect relationship is conditional on an employee's psychological empowerment.

\section{Sample and procedure}

Pureprofile provided UK participants from their online panel for Study 3. Participants were compensated $£ 2$ for completing the study. Participation was voluntary, with confidentiality and anonymity assured. Pureprofile notified 406 individuals about our study. As we had little control over participant selection, we used three screening criteria (screened out participants are reported in parentheses): a participant needed to be employed (89), to work for a direct supervisor (47), and to work in a team (16). Thus, 254 participants took part in our experiment; $57 \%$ were men, and the average age was 45 years $(S D=10.61)$.

We followed a similar design and procedure as Rusbult, Farrell, Rogers, and Mainous (1988). Participants were randomly assigned to one of eight conditions, with a 2 (low vs. high psychological empowerment) $\times 2$ (low PLMXD vs. high PLMXD) $\times 2$ (positive vs. negative quality relationship framing) between-subject design. Participants were asked to imagine that they worked in the environment presented in the respective vignette assigned. Each vignette contained a scenario with a description of the individual's level of psychological empowerment and PLMXD. In addition to randomly assigning participants to conditions, the presentation order of the empowerment and PLMXD descriptions also were randomized, and supplemental analysis (available upon request) indicated that presentation order had no effect on our results. Participants were instructed to place themselves mentally in the situation described and to indicate how they would react if they were the actual employee in the situation. Following the description of the hypothetical scenarios, participants were asked to complete a questionnaire that included, in the following order, employee perceptions of supervisor fairness (mediator) and job satisfaction (outcome). Participants were presented with scale items, which were also in a randomized order. Manipulation checks were carried out at the conclusion of the questionnaire. 


\section{Measures}

Manipulations: Psychological empowerment, PLMXD, and quality relationship framing

We manipulated psychological empowerment through variations in descriptions of the constructs of Spreitzer's (1995) empowerment scale. Participants in a high empowerment condition were shown the following vignette: 'In your workplace, you have a high level of freedom and discretion over your work. You set your own work agenda and deadlines. You have a lot of independent judgment when carrying out your work. Therefore, you feel confident about your ability to perform your work activities. You have a lot of control over your work and have significant influence over what happens in your workplace. Hence, the work you do is very important to you and is personally meaningful to you'. In contrast, participants allocated to the low empowerment condition, for example, were told that they had low levels of freedom and discretion over their work and that they could use very little independent judgment when carrying out their work.

PLMXD, however, cannot be simply conveyed in terms of perceptions of differential treatment; it should also take into account the relationship quality. Take the following two scenarios as examples. In Scenario 1, an employee perceives no differentiation in his or her workgroup but works in a group where everyone has a poor relationship with the leader. In Scenario 2, an employee reports no differentiation but is embedded in a workgroup where everyone has a good relationship with the leader. Both scenarios report low levels of PLMXD (in this example, no differentiation at all), yet their overall job satisfaction is likely to be affected by whether the framing of this scenario is positive or negative. Therefore, it is important to include this framing in our vignettes and model to ensure that framing is not driving the differentiation results and that our posited relationships hold, over and above quality relationship framing. As indicated, we randomly assigned positive and negative framing in our differentiation vignettes. We utilized four different vignettes for PLMXD: low vs. high PLMXD, with either positive or negative relationship quality framing. We drew upon Graen and Uhl-Bien's (1995) LMX-7 scale as inspiration when writing the vignettes. We illustrate the difference across vignettes between framing (positive/negative) and PLMXD (low/high) levels in Table 5. The following number of participants were randomly assigned to each of the eight conditions: (1) high empowerment, high PLMXD, and positive framing, 31 participants; (2) high empowerment, low PLMXD, and positive framing, 33 participants; (3) low empowerment, high PLMXD, and positive framing, 31 participants; (4) low empowerment, low PLMXD, and positive framing, 31 participants; (5) high empowerment, high PLMXD, and negative framing, 32 participants; (6) high empowerment, low PLMXD, and negative framing, 32 participants; (7) low empowerment, high PLMXD, and negative framing, 31 participants; and (8) low empowerment, low PLMXD, and negative framing, 33 participants.

\section{Mediator: Fairness perception}

We captured perceived supervisory fairness using the same 3-item scale as in Study 2 (Kim \& Leung, 2007; Cronbach's $\alpha=.96$ ).

\section{Outcome: Job satisfaction}

We captured job satisfaction using the same 5-item job satisfaction scale as in Studies 1 and 2 (Brayfield \& Rothe, 1951; Cronbach's $\alpha=.91$ ). Descriptive statistics of all variables are reported in Table 6. 


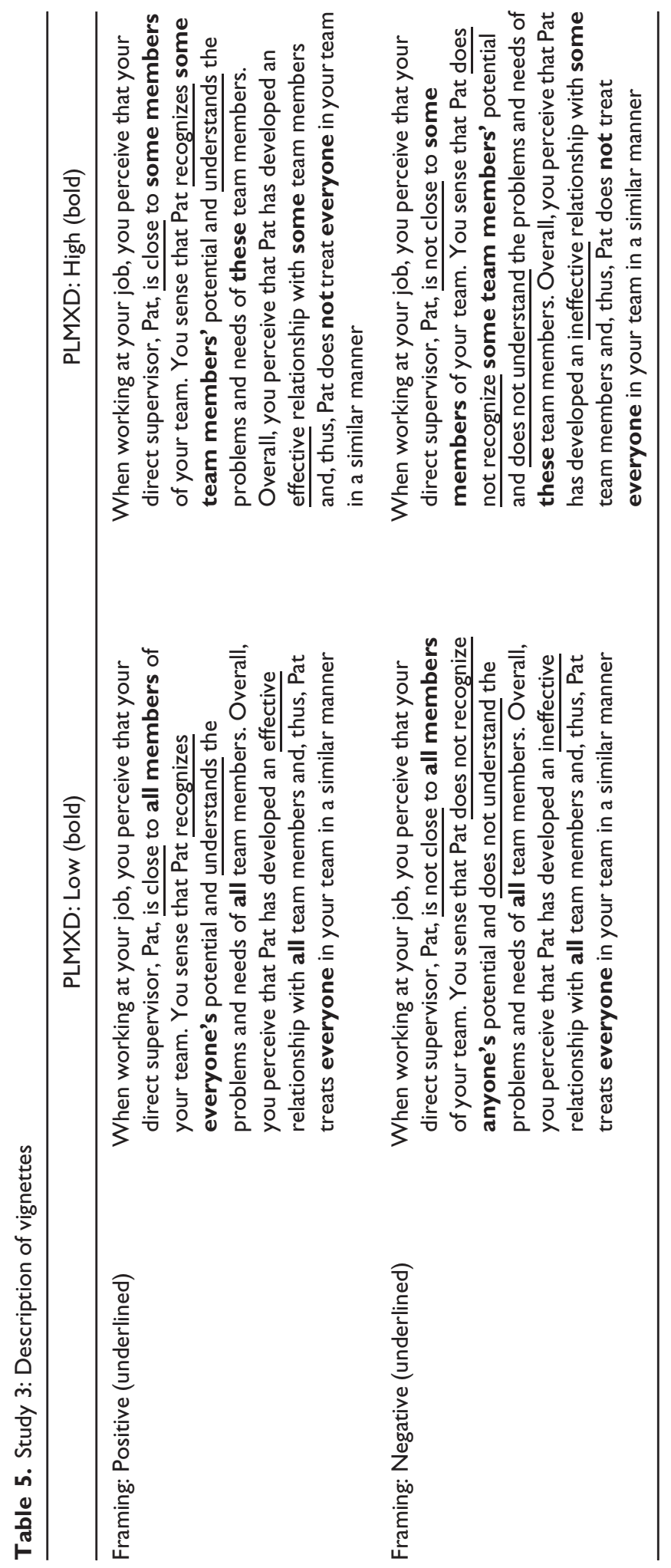


Table 6. Study 3: Means, standard deviations, andcorrelations $(N=254)$

\begin{tabular}{|c|c|c|c|c|c|c|c|}
\hline & \multicolumn{2}{|c|}{ Descriptive } & \multicolumn{5}{|c|}{ Correlations } \\
\hline & $M$ & $S D$ & I & 2 & 3 & 4 & 5 \\
\hline I. Relationship quality ${ }^{\mathrm{a}}$ & 0.50 & 0.50 & & & & & \\
\hline 2. PLMXDa & 0.49 & 0.50 & .00 & & & & \\
\hline 3. Psych. Empowerment ${ }^{a}$ & 0.50 & 0.50 & .01 & .00 & & & \\
\hline 4. Supervisory fairness & 3.58 & 1.88 & $.48 * * *$ & $-.37 * * *$ & $.13 *$ & $(.96)$ & \\
\hline 5. Job satisfaction & 3.85 & 1.53 & $.14 *$ & -.06 & $.63^{* * * *}$ & $.39 * * *$ & $(.91)$ \\
\hline
\end{tabular}

Notes. Values in parentheses Cronbach's alpha.

a Manipulated binary variables.

$* p<.05 ; * * p<.01 ; * * *<.001$.

\section{Manipulation checks}

We administered manipulation checks at the conclusion of the questionnaire, that is, after collecting data regarding the mediator (fairness perceptions) and outcome of interest (job satisfaction). We conducted manipulation checks for psychological empowerment, PLMXD, and quality relationship framing to ensure participants understood the vignettes. On a 7 -point Likert scale $(1=$ strongly disagree to $7=$ strongly agree $)$, participants indicated the extent to which they felt empowered in their job, as described in the vignette that was randomly assigned to them (i.e., did they agree that their job/role in the vignette facilitated them to have confidence, freedom, control, and meaning? Cronbach's $\alpha=.92)$. Participants randomly allocated to the low psychological empowerment condition reported significantly lower levels of empowerment $(M=2.72, S D=1.30$, $n=126$ ) than those assigned to the high psychological empowerment condition, $M=5.50, S D=1.02, n=128: t(252)=18.99, p=.00$. For the differentiation manipulation check, participants answered in terms of their level of agreement with three items (i.e., does the supervisor have similar relationships with teammates, treat teammates similarly, and provide the same support to teammates? Cronbach's $\alpha=.93$ ) using a 7point Likert scale. Participants randomly allocated to the low PLMXD condition indicated that the vignette supervisor treated teammates more similarly and, thus, was less differentiating $(M=5.52, S D=1.09, n=129)$ than in regard to those who were assigned to the high PLMXD condition, $M=2.85, S D=1.44, n=125: t(252)=16.73, p=.00$. Finally, participants were asked to indicate to what extent they agreed that the vignette included positive framing; that is, whether the quality of the relationship with the supervisor in the vignette was positive. Participants randomly assigned to vignettes that included positive framing indicated greater positive framing $(M=4.36, S D=1.76$, $n=126)$ than those who were assigned to the negative framing vignettes, $M=2.63$, $S D=1.58, n=128: t(252)=8.23, p=.00$. In summary, the manipulation checks provided evidence that the manipulations were understood as desired.

\section{Results}

In our analyses below, the PLMXD, psychological empowerment, and quality relationship framing manipulations are dichotomous variables (i.e., high and low PLMXD are 1 and 0 , respectively; high and low psychological empowerment are 1 and 0 , respectively; and positive and negative framing are 1 and 0 , respectively). As PLMXD and relationship 
quality framing are interdependent, we control for framing in all of our analyses in order to understand the influence of PLMXD above and beyond relationship quality framing. Additionally, we note that our mediator, employees' supervisory fairness perception, and our outcome, job satisfaction, are continuous, Likert scale variables immediately captured following the randomly assigned vignettes. We use Hayes' (2018) PROCESS methods as they allow us to test a moderated-mediation model with moderation on the second path, especially when the predictor and second-path moderator variables are (dichotomous) manipulations, and the mediator and outcome variables are Likert scale variables.

Before determining psychological empowerment's conditional indirect effect between PLMXD and job satisfaction via supervisory fairness perceptions, we tested Hypothesis 1 which suggests that fairness perceptions mediate between PLMXD - job satisfaction. We followed Hayes' (2018) PROCESS Model 4 in SPSS 24, that is, mediation model, using unstandardized coefficients and bootstrapping with 10,000 resamples to place $95 \%$ bias-corrected confidence intervals around our estimates. The findings show that PLMXD was negatively related to the employees' perceptions of supervisory fairness, $\beta=-1.37, S E=.19, p<.001 ; F(2,251)=71.23, p<.001, R^{2}=.36$, and the employees' fairness perceptions were positively related to job satisfaction, $\beta=0.38, S E=.06$, $p<.001 ; F(3,250)=16.37, p<.001, R^{2}=.16$; i.e., also controlling for vignette framing. However, the direct effect between PLMXD and job satisfaction was not significant. Combining these effects, we determined that the indirect effect of PLMXD on job satisfaction via supervisory fairness perceptions was -0.52 with a $95 \%$ CI $[-0.74 ;-0.33]$. The evidence therefore supports Hypothesis 1.

To test whether it is through fairness that the effect between PLMXD and job satisfaction becomes stronger (or weaker) as psychological empowerment decreases (or increases), we used Model 14 from Hayes' (2018) PROCESS to test this second-stage moderated-mediation relationship in SPSS 24 (see Clarkson, Smith, Tormala, \& Dugan, 2017; Mooijman, van Dijk, Van Dijk, \& Ellemers, 2017; and Welsh, Ellis, Christian, \& Mai, 2014 for similar examples of experimental studies testing moderated mediation, with a second-path moderator). Following Hayes' procedure, we estimated the conditional indirect effect of PLMXD on job satisfaction, through fairness perception, under high versus low conditions of psychological empowerment. We used unstandardized coefficients and bootstrapping with 10,000 resamples, to place $95 \%$ bias-corrected confidence intervals around estimates of the indirect effects. Results are reported in Table 7. The first path of the model predicting fairness perceptions was found to be significant, with PLMXD negatively predicting fairness perceptions, $\beta=-1.37, S E=.19$, $p<.001 ; F(2,251)=71.23, p<.001, R^{2}=.36$.

For job satisfaction, as psychological empowerment increased, the strength of the significant negative conditional indirect effect of PLMXD on job satisfaction through fairness perceptions became weaker: low psychological empowerment (coefficient $=-0.49,95 \% \mathrm{CI}[-0.72 ;-0.29])$ as compared to high psychological empowerment (coefficient $=-0.27,95 \% \mathrm{CI}[-0.46 ;-0.11]$ ), as indicated by the significant interaction between psychological empowerment and fairness perceptions, $\beta=-0.16, S E=.07$, $p<.05 ; F(5,248)=50.82, p<.001, R^{2}=.51$. We ran the index of moderated mediation (Hayes, 2015) to further verify psychological empowerment's attenuation effect on the PLMXD - fairness perceptions - job satisfaction-mediated relationship. Given empowerment is dichotomous, the index is a test of equality of the conditional indirect effects for the low versus high empowerment groups. The index was 0.21 and the $95 \%$ confidence interval did not include zero (95\% CI $[0.01 ; 0.43])$, which indicates that the difference in magnitude between the low versus high indirect effects is significant. The 
Table 7. Study 3: Moderated-mediation analyses using psychological empowerment as a second-path moderator of the relationships among PLMXD, fairness, and job satisfaction

\begin{tabular}{|c|c|c|c|c|}
\hline & \multicolumn{2}{|c|}{ PLMXD - Fairness } & \multicolumn{2}{|c|}{$\begin{array}{c}\text { PLMXD - Fairness - Job } \\
\text { satisfaction }\end{array}$} \\
\hline & \multicolumn{2}{|c|}{ Fairness } & \multicolumn{2}{|c|}{ Job satisfaction } \\
\hline & $\beta(S E)$ & $95 \% \mathrm{Cl}$ & $\beta(S E)$ & $95 \% \mathrm{Cl}$ \\
\hline Relationship quality (framing) & $1.79(.19)^{* * * *}$ & $1.41: 2.16$ & $-0.06(.16)$ & $-0.37: 0.25$ \\
\hline PLMXD & $-1.37(.19)^{* * * *}$ & $-1.74:-1.00$ & $0.20(.15)$ & $-0.10: 0.49$ \\
\hline Supervisory fairness & & & $0.36(.06)^{* * * *}$ & $0.24: 0.47$ \\
\hline Psych. Empowerment & & & $2.34(.30) * * *$ & 1.76: 2.93 \\
\hline $\begin{array}{l}\text { Fairness } \times \text { Psych. } \\
\text { Empowerment }\end{array}$ & & & $-0.16(.07)^{*}$ & $-0.30:-0.01$ \\
\hline Model summary & \multicolumn{2}{|c|}{$R^{2}=.36 ; F(2,25 I)=7 \mid .23 ; p<.00 I$} & \multicolumn{2}{|c|}{$R^{2}=.5 I ; F(5,248)=50.82 ; p<.00$} \\
\hline
\end{tabular}

Notes. The framing, PLMXD, and empowerment variables are dichotomous.

Two-tailed test. ${ }^{*} p<.05 ; * * p<.01 ; * * * p<.001$.

indirect relationship between PLMXD and job satisfaction through fairness perceptions is more strongly negative for those who were assigned to the low empowerment condition than the high empowerment condition, supporting Hypothesis 2 . We further note that, in our conditional indirect effect analysis, we produced an identical indirect effect coefficient, as determined above in the mediation analysis, confirming support for Hypothesis 1.

\section{Discussion}

As Kauppila (2016) noted, a central yet unanswered question in LMX differentiation research is when and how does LMX differentiation influence followers' work attitudes and outcomes? While Kauppila examined the effects of group-level LMX differentiation on followers' attitudes and outcomes, we chose to address this question by examining how and when individual perceptions of LMX differentiation have an impact on group members' work attitudes and, more precisely, on job satisfaction. We developed and tested, using a three-study approach, our theoretical model, which revealed one mechanism (i.e., supervisory fairness perceptions) and one boundary condition (i.e., psychological empowerment) of the relationship between PLMXD and job satisfaction.

This study contributes to knowledge on LMX differentiation in several ways. It extends the LMX differentiation literature by refining our understanding of the role played by individual perceptions of LMX differentiation in the workplace. It not only corroborates previous studies, which suggest that employees negatively react to PLMXD (Hooper \& Martin, 2008a, 2008b; Yuan \& Jian, 2012), but also discusses how (i.e., through an explanatory mechanism and mediation) and under which circumstances (i.e., through boundary conditions and moderation) such a negative association is more likely to occur. We further extend the literature by connecting our mechanism and boundary condition contributions together and thereby revealing the first conditional indirect relationship in the individual-level LMX differentiation literature. 
To our knowledge, we provide one of the first, if not the first, empirical test of supervisory fairness perceptions, explaining the indirect relationship between PLMXD and job satisfaction. Two previous studies have investigated more distal mechanisms, such as team trust (Yuan \& Jian, 2012) and team conflict (Hooper \& Martin, 2008a), in order to explain the connection between PLMXD and workplace attitudes. Both studies discussed the potential for supervisory fairness perceptions to explain the relationship between PLMXD and team dynamics (Hooper \& Martin, 2008a, 2008b; Yuan \& Jian, 2012), yet no study has empirically tested for this theoretical mechanism. By focusing on supervisory fairness perceptions, a more proximal mechanism which is likely to be a precursor to these team dynamic mechanisms, our study sheds light on and strengthens the essential role of fairness perceptions in explaining the relationship between PLMXD and work attitudes.

Furthermore, the literature has yet to investigate the boundary conditions under which the negative outcomes of PLMXD may be assuaged or exacerbated. Previous studies generally assume that employees respond uniformly to PLMXD. We report that employees do not necessarily respond to PLMXD in the same way and, in fact, the harmful effects of PLMXD are not as strongly experienced by psychologically empowered employees. This study further illustrates the importance and strength of providing one's employees with the ability to actively participate in the workplace and have some say in the tasks that they carry out. Collectively, our results suggest that, even though they report greater levels of PLMXD, empowered employees are more likely to remain satisfied in their job as the fairness perceptions they derive from their feelings of empowerment can counterbalance the supervisory unfairness perceptions experienced as a result of PLMXD.

Additionally, our study makes a methodological contribution to the LMX differentiation literature. Prior to this study, PLMXD was captured either using indirect individualsource measures (Epitropaki et al., 2016; Hooper \& Martin, 2008a; Yuan \& Jian, 2012) or direct individual-source measures (Chiniara \& Bentein, 2018; Van Breukelen et al., 2012). PLMXD had not been captured through an experimental design. We created and implemented vignettes that captured leaders' differential treatment at different levels of treatment quality (i.e., positive/negative framing). By doing so, we illustrate how future research can benefit from using different study designs that constructively replicate (Lykken, 1968) one another, so as to provide greater support for the robustness of their theories and hypothesized relationships. It is our hope that future scholarly investigations continue to explore experimental designs, in order to study similar questions, and that they can use our approach to complement their efforts.

This study also contributes to the empowerment literature. From an empirical perspective, given that previous research has not attempted to conjunctively study psychological empowerment and LMX differentiation, we provide new evidence of the beneficial effects of psychological empowerment in organizations. From a theoretical perspective, we suggest that the effects of psychological empowerment might be better understood if analyzed from an organizational justice theory perspective. We contend that psychological empowerment is closely related to the formation of fairness perceptions (Chi \& Han, 2008; Ritter et al., 2014), which in turn act as a remedy that buffers the negative effects of PLMXD on job satisfaction through supervisory unfairness perceptions. Furthermore, contrary to the majority of psychological empowerment research, which has looked at this construct as a mediator, we explore its moderating effect. Maynard et al. (2012) concluded their review on individual-level psychological empowerment by noting that not enough studies have considered psychological empowerment as a moderator. Hence, this paper addresses their call by theorizing and empirically demonstrating that empowered employees are better equipped to face perceptions of differential treatment from their leader. 


\section{Implications for practice}

Our findings have important practical implications. First, they suggest that employees tend to perceive LMX differentiation as constituting unfair treatment on their leaders' part. Leaders should hence reflect on how to attenuate such unfairness perceptions. One possibility would be for leaders to openly discuss LMX differentiation with their employees. An open discussion could clarify the situation, reassure followers, and attenuate feelings of unfair treatment. If leaders are able to have a positive impact on the more proximal employee responses, such as supervisory fairness perceptions, then they may be able to control or eliminate the more distal team consequences, such as team conflict, team distrust, and negative attitudinal outcomes. Second, our findings reinforce the necessity for organizations to implement and promote empowerment initiatives. As leaders typically differentiate among workgroup members (Liden \& Graen, 1980), it is important that leaders not only acknowledge the potential detrimental effects of LMX differentiation but also, in order to counterbalance those effects, ensure that employees are empowered to account for the natural phenomena of LMX differentiation. Decades of empowerment research has informed and equipped organizations with tools to promote psychological empowerment, such as work design (task significance, feedback, skill variety, task complexity, and autonomy; see Hackman \& Oldham, 1980), structural empowerment (employees are autonomous and responsible for a task), and organizational support (climate and culture of empowerment) (Maynard et al., 2012). Leaders should not only rely on a top-down approach to empowerment (i.e., initiatives listed above) but also adopt a bottom-up approach which encourages followers to empower themselves. For example, job crafting initiatives as well as proactive behaviours should be encouraged. Circumventing the negative consequences of LMX differentiation by empowering employees could also lead to positive spill-over effects for organizations in terms of employees' commitment to their organizations (Chen \& Kanfer, 2006), organizational citizenship behaviours (Seibert et al., 2011), and improved performance (Spreitzer et al., 1997).

\section{Potential limitations and future research}

As is the case for any empirical investigation, the current study is subject to potential limitations. We acknowledge that our field data (Study 1, Study 2) were self-reported, introducing common method variance as a potential influence on our results, even though we took several initiatives to minimize the effects of common method bias (Podsakoff et al., 2012). First, we collected our survey data over time by collecting them in separate waves, separated by a 1-week time lag between end of the last wave and the beginning of the next wave. Second, the response format for our key independent variable, PLMXD (which was assessed by computing the coefficient of the variation in the respondents' perceived LMX scores for each of their teammates), is likely to reduce the potential effect of common-source variance. Indeed, it is unlikely that participants could have guessed what we were assessing; they therefore could not have had the knowledge necessary to manipulate their scores. Furthermore, research suggests that the use of different response scales for the independent variable and dependent variables (i.e., PLMXD based on a sorting task, job satisfaction based on a multi-item scale evaluated on a Likert scale) can interrupt stylistic responses and ultimately reduce any spurious relationships between the independent and dependent variables (Gardner, Cummings, Dunham, \& Pierce, 1998).

Our third study closely followed Aguinis and Bradley's (2014) suggestions for vignette experiments. This experimental design provides a constructive replication of our field study results and is the first vignette-based experiment to manipulate PLMXD. However, 
we acknowledge that our vignette experiment raises ecological validity concerns, which has the potential to limit the generalizability of our findings. Additionally, although we randomly assigned participants across manipulated conditions, we measured our mediator and outcome variables at the same time. As we did not manipulate our mediating variable (supervisory fairness), we should be cautious when making causal claims, as the relationship between supervisory fairness and job satisfaction should be interpreted as correlational and could be explained by method variance (Pirlott \& MacKinnon, 2016). However, method variance cannot explain the significant interaction regarding the way in which psychological empowerment manipulation and supervisory fairness were found to predict job satisfaction (Evans, 1985; McClelland \& Judd, 1993). Although our results suggest a conditional indirect effect, they should be interpreted with caution. Given our experiment's limitations, we welcome future research that uses different manipulation techniques (e.g., video observation manipulation) or a longitudinal, panel data design to confirm our results.

We see several avenues for future research. The literature has evidenced that LMX can facilitate greater levels of employees' psychological empowerment (Liden et al., 2000) and could therefore potentially influence the moderating effect of psychological empowerment on the relationship between PLMXD and job satisfaction. Following a reviewer's suggestion, we tested a three-way interaction (i.e., PLMXD x psychological empowerment $\times$ LMX) predicting job satisfaction (PROCESS Model 3, Study 1 and Study 2). We also tested a conditional indirect effect between PLMXD and job satisfaction via supervisory fairness, with the three-way interaction, at the second stage of the study (i.e., supervisory fairness $\times$ psychological empowerment $\times$ LMX; PROCESS Model 18, Study 2). Our current data and results do not support the inclusion of LMX along with psychological empowerment as a moderator; however, future research should further examine the way in which these constructs can work in tandem.

As recent studies have revealed the benefits of group-level LMX differentiation on individual outcomes, such as helping behaviour (Erdogan \& Bauer, 2010), individual performance (Naidoo, Scherbaum, Goldstein, \& Graen, 2011), and work engagement and organization citizenship behaviours (Matta, Scott, Koopman, \& Conlon, 2015), one cannot overlook that positive outcomes of individual-level LMX differentiation might occur. For example, Sias and Jablin (1995) discussed how differences in perceived differential treatment can increase communication among co-workers. More recently, Chiniara and Bentein (2018) found that low levels of PLMXD strengthened team cohesion, which in turn positively influenced team task performance and service-oriented organizational citizenship behaviours. It has also been suggested that employees with low LMX levels who perceive that differentiation exists within their workgroup may recognize that there is an opportunity to change their status and develop better relationships with their leader (Kauppila, 2016; Liden, Erdogan, Wayne, \& Sparrowe, 2006). Yet, individual-level LMX research, including this study, has so far focused its attention on negative outcomes of PLMXD. We hence call for future research examining the specific conditions under which high PLMXD leads to positive outcomes.

Finally, as PLMXD is a subjective perception that is unique to each employee within a workgroup, we cannot assume that all team members construe their PLMXD using the same criteria, nor can we assume that all team members accurately capture the variability of LMX relationships within the workgroup. For example, a leader dedicating more time to helping a team member could be noticed by a member but go unnoticed by another, which could trigger higher levels of PLMXD for one member, but not for the other. As PLMXD is likely to be associated with negative employee reactions, we 
welcome future research examining whether specific leadership behaviours are more or less likely to be interpreted as a sign of greater variability in LMX relationships within their workgroup.

\section{Conclusion}

This study contributes to the emerging literature on individual-level LMX differentiation by refining our understanding of the ways in which PLMXD operates. We not only shed light on one of the mechanisms that can explain the negative relationship between PLMXD and job satisfaction, but we also provide new evidence that this negative relationship is not uniform across all employees. This three-study investigation highlights the way in which psychological empowerment moderates the relationship between PLMXD and job satisfaction, and suggests that this moderated relationship can be explained through fairness perceptions. This study highlights why it is essential for organizations to empower their employees, so they can counterbalance the potential negative effects of PLMXD.

\section{References}

Aguinis, H., \& Bradley, K. J. (2014). Best practice recommendations for designing and implementing experimental vignette methodology studies. Organizational Research Methods, 17(4), 351371. https://doi.org/10.1177/1094428114547952

Aiken, L. S., \& West, S. G. (1991). Multiple regression: Testing and interpreting interactions. Newbury Park, CA: Sage.

Anand, S., Hu, J., Liden, R. C., \& Vidyarthi, P. R. (2011). Leader-Member Exchange: Recent research findings and prospects for the future. In A. Bryman, D. Collinson, K. Grint, B. Jackson \& M. UhlBien (Eds.), The SAGE handbook of leadership (pp. 311-325). London, UK: Sage.

Anand, S., Vidyarthi, P. R., \& Park, H. S. (2015). LMX differentiation: Understanding relational leadership at individual and group levels. In T. N. Bauer \& B. Erdogan (Eds.), Oxford handbook of Leader-Member Exchange (pp. 263-291). New York, NY: Oxford University Press.

Bates, D., Maechler, M., Bolker, B., \& Walker, S. (2015). Fitting linear mixed-effects models using lme4. Journal of Statistical Software, 67(1), 1-48. https://doi.org/10.18637/jss.v067.i01

Blader, S. L., \& Tyler, T. R. (2003). A four-component model of procedural justice: Defining the meaning of a "fair" process. Personality and Social Psychology Bulletin, 29(6), 747-758. https://doi.org/10.1177/0146167203029006007

Blader, S. L., \& Tyler, T. R. (2015). Relational models of procedural justice. In R. S. Cropanzano \& M. L. Ambrose (Eds.), The Oxford handbook of justice in the workplace. Oxford, NY: Oxford University Press. https://doi.org/10.1093/oxfordhb/9780199981410.013.16

Bolino, M. C., \& Turnley, W. H. (2009). Relative deprivation among employees in lower-quality Leader-Member Exchange relationships. Leadership Quarterly, 20(3), 276-286. https://doi. org/10.1016/j.leaqua.2009.03.001

Brayfield, A. H., \& Rothe, H. F. (1951). An index of job satisfaction. Journal of Applied Psychology, 35, 307-311. https://doi.org/10.1037/h0055617

Brislin, R. W. (1970). Back-translation for cross-cultural research. Journal of Cross-Cultural Psychology, 1(3), 185-216. https://doi.org/10.1177/135910457000100301

Chamberlin, M., Newton, D. W., \& LePine, J. A. (2018). A meta-analysis of empowerment and voice as transmitters of high-performance managerial practices to job performance. Journal of Organizational Behavior, 39(10), 1296-1311. https://doi.org/10.1002/job.2295

Chen, G., \& Kanfer, R. (2006). Toward a systems theory of motivated behavior in work teams. Research in Organizational Behavior, 27, 223-267. https://doi.org/10.1016/S0191-3085(06) 27006-0 
Chen, G., \& Klimoski, R. J. (2003). The impact of expectations on newcomer performance in teams as mediated by work characteristics, social exchanges, and empowerment. Academy of Management Journal, 46(5), 591-607. https://doi.org/10.5465/30040651

Chi, N., \& Han, T. (2008). Exploring the linkages between formal ownership and psychological ownership for the organization, the mediating role of organizational justice. Journal of Occupational and Organizational Psychology, 81, 691-711. https://doi.org/10.1348/ $096317907 X 262314$

Chiniara, M., \& Bentein, K. (2018). The servant leadership advantage: When perceiving low differentiation in leader-member relationship quality influences team cohesion, team task performance and service OCB. Leadership Quarterly, 29(2), 333-345. https://doi.org/10.1016/ j.leaqua.2017.05.002

Clarkson, J., Smith, E., Tormala, Z., \& Dugan, R. (2017). Group identification as a means of attitude restoration.Journal of Experimental Social Psychology, 68, 139-145. https://doi.org/10.1016/ j.jesp.2016.07.001

Cohen-Charash, Y., \& Spector, P. E. (2001). The role of justice in organizations: A meta-analysis. Organizational Behavior and Human Decision Processes, 86(2), 278-321. https://doi.org/10. 1006/obhd.2001.2958

Colquitt, J. A., Conlon, D. E., Wesson, M. J., Porter, C. O., \& Ng, K. Y. (2001). Justice at the millennium: A meta-analytic review of 25 years of organizational justice research. Journal of Applied Psychology, 86(3), 425-445. https://doi.org/10.1037//0021-9010.86.3.425

Deutsch, M. (1975). Equity, equality, and need: What determines which value will be used as the basis of distributive justice? Journal of Social Issues, 31, 137-149. https://doi.org/10.1111/j. 1540-4560.1975.tb01000.x

Dunegan, K. J., Duchon, D., \& Uhl-Bien, M. (1992). Examining the link between Leader-Member Exchange and subordinate performance: The role of task analyzability and variety as moderators. Journal of Management, 18(1), 59-76. https://doi.org/10.1177/014920639201800105

Epitropaki, O., Kapoutsis, I., Ellen, B. P., Ferris, G. R., Drivas, K., \& Ntotsi, A. (2016). Navigating uneven terrain: The roles of political skill and LMX differentiation in prediction of work relationship quality and work outcomes. Journal of Organizational Behavior, 37, 1078-1103. https://doi.org/10.1002/job.2100

Erdogan, B., \& Bauer, T. N. (2010). Differentiated leader-member exchanges: The buffering role of justice climate. Journal of Applied Psychology, 95(6), 1104-1120. https://doi.org/10.1037/ a0020578

Evans, M. G. (1985). A Monte Carlo study of the effects of correlated method variance in moderated multiple regression analysis. Organizational Behavior and Human Decision Processes, 36, 305-323. https://doi.org/10.1016/0749-5978(85)90002-0

Gardner, D. G., Cummings, L. L., Dunham, R. B., \& Pierce, J. L. (1998). Single-item versus multipleitem measurement scales: An empirical comparison. Educational and Psychological Measurement, 58, 898-915. https://doi.org/10.1177/0013164498058006003

Gerstner, C. R., \& Day, D. V. (1997). Meta-analytic review of Leader-Member Exchange theory: Correlates and construct issues. Journal of Applied Psychology, 82, 827-844. https://doi.org/ 10.1037/0021-9010.82.6.827

Graen, G. B., \& Uhl-Bien, M. (1995). Relationship-based approach to leadership: Development of Leader-Member Exchange (LMX) theory of leadership over 25 years: Applying a multi-level multi-domain perspective. Leadership Quarterly, 6(2), 219-247. https://doi.org/10.1016/ 1048-9843(95)90036-5

Green, F., Felstead, A., Gallie, D., \& Inanc, H. (2013).Job-related well-being in Britain: First findings from the Skills and Employment Survey 2012. London, UK: Centre for Learning and Life Chances in Knowledge Economies and Societies, Institute of Education.

Hackman, J. R., \& Oldham, G. R. (1980). Work redesign. Reading, MA: Addison-Wesley.

Harris, K. J., Wheeler, A. R., \& Kacmar, K. M. (2009). Leader-Member Exchange and empowerment: Direct and interactive effects on job satisfaction, turnover intentions, and performance. Leadership Quarterly, 20(3), 371-382. https://doi.org/10.1016/j.leaqua.2009.03.006 
Hayes, A. F. (2015). An index and test of linear moderated mediation. Multivariate Behavioral Research, 50(1), 1-22. https://doi.org/10.1080/00273171.2014.962683

Hayes, A. F. (2018). Introduction to mediation, moderation, and conditional process analysis: $A$ regression-based approach (2nd ed.). New York, NY: Guilford Press.

Henderson, D. J., Liden, R. C., Glibkowski, B. C., \& Chaudhry, A. (2009). LMX differentiation: A multilevel review and examination of its antecedents and outcomes. Leadership Quarterly, 20 (4), 517-534. https://doi.org/10.1016/j.leaqua.2009.04.003

Hooper, D. T., \& Martin, R. (2008a). Beyond personal Leader-Member Exchange (LMX) quality: The effects of perceived LMX variability on employee reactions. Leadership Quarterly, 19, 20-30. https://doi.org/10.1016/j.leaqua.2007.12.002

Hooper, D. T., \& Martin, R. (2008b). Measuring perceived LMX variability within teams and its impact on procedural justice climate. In A. Glendon, B. M. Thompson \& B. Myors (Eds.), Advances in organisational psychology (pp. 249-264). Bowen Hills, Qld: Australian Academic Press.

Kauppila, O. P. (2016). When and how does LMX differentiation influence followers' work outcomes? The interactive roles of one's own LMX status and organizational context. Personnel Psychology, 69, 357-393. https://doi.org/10.1111/peps.12110

Keller, T., \& Dansereau, F. (1995). Leadership and empowerment: A social exchange perspective. Human Relations, 48, 127-146. https://doi.org/10.1177/001872679504800202

Kim, T. Y., \& Leung, K. (2007). Forming and reacting to overall fairness: A cross-cultural comparison. Organizational Behavior and Human Decision Processes, 104(1), 83-95. https://doi.org/10. 1016/j.obhdp.2007.01.004

Kristof-Brown, A., Zimmerman, R. D., \& Johnson, E. C. (2005). Consequences of individuals' fit at work: A meta-analysis of person-job, person-organization, person-group, and person-supervisor fit. Personnel Psychology, 58(2), 281-342. https://doi.org/10.1111/j.1744-6570.2005.00672.x

Leventhal, G. S. (1980). What should be done with equity theory? New approaches to the study of fairness in social relationships. In K. Gergen, M. Greenberg \& R. Willis (Eds.), Social exchange: Advances in theory and research (pp. 27-55). New York, NY: Plenum.

Liden, R. C., Erdogan, B., Wayne, S. J., \& Sparrowe, R. T. (2006). Leader-Member Exchange, differentiation, and task interdependence: Implications for individual and group performance. Journal of Organizational Behavior, 27, 1-24. https://doi.org/10.1002/job.409

Liden, R. C., \& Graen, G. (1980). Generalizability of the vertical dyad linkage model of leadership. Academy of Management Journal, 23(3), 451-465. https://doi.org/10.2307/255511

Liden, R. C., Sparrowe, R. T., \& Wayne, S. J. (1997). Leader-Member Exchange theory: The past and potential for the future. In G. R. Ferris (Ed.), Research in personnel and buman resources management (Vol. 15, pp. 47-120). Greenwich, CT: JAI Press.

Liden, R. C., Wayne, S. J., \& Sparrowe, R. T. (2000). An examination of the mediating role of psychological empowerment on the relations between the job, interpersonal relationships, and work outcomes. Journal of Applied Psychology, 85(3), 407-416. https://doi.org/10.1037/00219010.85.3.407

Lind, E. A., \& Tyler, T R.. (1988). The social psychology of procedural justice. New York: Plenum.

Lykken, D. (1968). Statistical significance in psychological research. Psychological Bulletin, 70 , 151-159. https://doi.org/10.1037/h0026141

Martin, R., Epitropaki, O., Thomas, G., \& Topakas, A. (2010). A review of Leader-Member Exchange research: Future prospects and directions. In G. P. Hodgkinson \& J. K. Ford (Eds.), International review of industrial and organizational psychology (vol. 25, pp. 35-89). Chichester, UK: Wiley.

Martin, R., Thomas, G., Legood, A., \& Dello Russo, S. (2018). Leader-Member Exchange (LMX) differentiation and work outcomes: Conceptual clarification and critical review. Journal of Organizational Behavior, 39(2), 151-168. https://doi.org/10.1002/job.2202

Matta, F. K., Scott, B. A., Koopman, J., \& Conlon, D. E. (2015). Does seeing "eye to eye" affect work engagement and organizational citizenship behavior? A role theory perspective on LMX agreement. Academy of Management Journal, 58, 1686-1708. https://doi.org/10.5465/amj. 2014.0106 
Maynard, M. T., Gilson, L. L., \& Mathieu, J. E. (2012). Empowerment - fad or fab? A multilevel review of the past two decades of research. Journal of Management, 38, 1231-1281. https://doi.org/ $10.1177 / 0149206312438773$

McClelland, G. H., \& Judd, C. M. (1993). Statistical difficulties of detecting interactions and moderator effects. Psychological Bulletin, 114, 376-390. https://doi.org/10.1037/0033-2909. 114.2.376

McFarlin, D. B., \& Sweeney, P. D. (1992). Distributive and procedural justice as predictors of satisfaction with personal and organizational outcomes. Academy of Management Journal, 35, 626-637. https://doi.org/10.5465/256489

Mooijman, M., van Dijk, W. W., Van Dijk, E., \& Ellemers, N. (2017). On sanction-goal justifications: How and why deterrence justifications undermine rule compliance. Journal of Personality and Social Psychology, 112(4), 577-588. https://doi.org/10.1037/pspi0000084

Mora, J. G., Aracil, A. G., \& Vila, L. E. (2007). Job satisfaction among young European higher education graduates. Higher Education, 53, 29-59. https://doi.org/10.1007/s10734-005-23774

Naidoo, L. J., Scherbaum, C. A., Goldstein, H. W., \& Graen, G. B. (2011). A longitudinal examination of the effects of LMX, ability, and differentiation on team performance. Journal of Business and Psychology, 26(3), 347-357. https://doi.org/10.1007/s10869-010-9193-2

Pirlott, A. G., \& MacKinnon, D. P. (2016). Design approaches to experimental mediation. Journal of Experimental Social Psychology, 66, 29-38. https://doi.org/10.1016/j.jesp.2015.09.012

Podsakoff, P. M., MacKenzie, S. B., \& Podsakoff, N. P. (2012). Sources of method bias in social science research and recommendations on how to control it. Annual Review of Psychology, 63, 539569. https://doi.org/10.1146/annurev-psych-120710-100452

$\mathrm{R}$ Core Team (2018). R: A language and environment for statistical computing. Vienna, Austria: $\mathrm{R}$ Foundation for Statistical Computing. Retrieved from https://www.R-project.org/

Raub, S., \& Robert, C. (2013). Empowerment, organizational commitment, and voice behaviour in the hospitality industry evidence from a multinational sample. Cornell Hospitality Quarterly, 54, 136-148. https://doi.org/10.1177/1938965512457240

Reb, J., Goldman, B. M., Kray, L. J., \& Cropanzano, R. (2006). Different wrongs, different remedies? Reactions to organizational remedies after procedural and interactional injustice. Personnel Psychology, 59(1), 31-64. https://doi.org/10.1111/j.1744-6570.2006.00773.x

Ritter, B. A., Venkatraman, S., \& Schlauch, C. (2014). A multi-level exploration of empowerment mediators. Leadership and Organization Development Journal, 35(7), 649-667. https://doi. org/10.1108/LODJ-07-2012-0085

Rose, M. (2005). Job satisfaction in Britain: Coping with complexity. British Journal of Industrial Relations, 43(3), 455-467. https://doi.org/10.1111/j.1467-8543.2005.00364.x

Rusbult, C. E., Farrell, D., Rogers, G., \& Mainous, A. G. (1988). Impact of exchange variables on exit, voice, loyalty, and neglect: An integrative model of responses to declining job satisfaction. Academy of Management Journal, 31, 599-627. https://doi.org/10.2307/256461

Scandura, T. A. (1999). Rethinking Leader-Member Exchange: An organizational justice perspective. Leadership Quarterly, 10, 25-40. https://doi.org/10.1016/S1048-9843(99)80007-1

Seibert, S. E., Silver, S. R., \& Randolph, W. A. (2004). Taking empowerment to the next level: A multiple-level model of empowerment, performance, and satisfaction. Academy of Management Journal, 47(3), 332-349. https://doi.org/10.2307/20159585

Seibert, S. E., Wang, G., \& Courtright, S. H. (2011). Antecedents and consequences of psychological and team empowerment in organizations: A meta-analysis review. Journal of Applied Psychology, 96, 981-1003. https://doi.org/10.1037/a0022676

Sias, P. M., \& Jablin, F. M. (1995). Differential superior-subordinate relations, perceptions of fairness, and coworker communication. Human Communication Research, 22(1), 5-37. https://doi. org/10.1111/j.1468-2958.1995.tb00360.x

Spreitzer, G. M. (1995). Psychological empowerment in the workplace: Dimensions, measurement, and validation. Academy of Management Journal, 38, 1442-1465. https://doi.org/10.2307/ 256865 
Spreitzer, G. M. (1996). Social structural characteristics of psychological empowerment. Academy of management journal, 39(2), 483-504. https://doi.org/10.5465/256789

Spreitzer, G. M., Kizilos, M. A., \& Nason, S. W. (1997). A dimensional analysis of the relationship between psychological empowerment and effectiveness, satisfaction, and strain. Journal of Management, 23, 679-704. https://doi.org/10.1177/014920639702300504

Thibaut, J. W., \& Walker, L. (1975). Procedural justice: A psychological perspective. Hillsdale, NJ: Erlbaum.

Thomas, G., Martin, R., Epitropaki, O., Guillaume, Y. R. F., \& Lee, A. (2013). Social cognition in leader-follower relationships: Applying insights from relationship science to understanding relationship-based approaches to leadership. Journal of Organizational Behavior, 34, 63-81.

Tyler, T. R. (1989). The psychology of procedural justice: A test of the group-value model.Journal of Personality and Social Psychology, 57, 830-838. https://doi.org/10.1037/0022-3514.57.5.830

Tyler, T. R. (1990). Why people obey the law. New Haven, CT: Yale University Press.

Van Breukelen, W., Konst, D., \& Van Der Vlist, R. (2002). Effects of LMX and differential treatment on work unit commitment. Psychological Reports, 91(1), 220-230. https://doi.org/10.2466/pro. 2002.91.1.220

Van Breukelen, W., Van Der Leeden, R., Wesselius, W., \& Hoes, M. (2012). Differential treatment within sports teams, leader-member (coach-player) exchange quality, team atmosphere, and team performance. Journal of Organizational Behavior, 33, 43-63. https://doi.org/10.1002/ job. 735

Vecchio, R. P. (2005). Explorations in employee envy: Feeling envious and feeling envied. Cognition and Emotion, 19(1), 69-81. https://doi.org/10.1080/02699930441000148

Welsh, D. T., Ellis, A. P., Christian, M. S., \& Mai, K. M. (2014). Building a self-regulatory model of sleep deprivation and deception: The role of caffeine and social influence. Journal of Applied Psychology, 99, 1268-1277. https://doi.org/10.1037/a0036202

Yu, A., Matta, F. K., \& Cornfield, B. (2018). Is LMX differentiation beneficial or detrimental for group effectiveness? A meta-analytic investigation and theoretical integration Academy of Management Journal, 61, 1158-1188. https://doi.org/10.5465/amj.2016.1212

Yuan, N., \& Jian, L. (2012). The mediating role of trust in teammates in the relationship between differentiation in Leader-Member Exchange (LMX) and work attitude: An empirical study in China. African Journal of Business Management, 6, 9617-9625. https://doi.org/10.5897/ AJBM11.280

Received 26 March 2018; revised version received I2 March 2019 